\title{
EVALUASI PELAKSANAAN PEREKAMAN KARTU TANDA PENDUDUK ELEKTRONIK DI DINAS KEPENDUDUKAN DAN CATATAN SIPIL KABUPATEN BUTON
}

\author{
La Asiri' \\ 1Program Studi Ilmu Pemerintahan, \\ Fakultas Ilmu Sosial dan Ilmu Politik Universitas Muhammadiyah Buton \\ E-mail: laasiriaris72@gmail.com
}

\begin{abstract}
Abstrak; Tujuan dari penelitian ini adalah untuk mengetahui Evaluasi Pelaksanaan Perekaman KTP-el di Dinas Kependudukan dan Pencatatan Sipil Kabupaten Buton. Penelitian ini menggunakan teori kriteria evaluasi William N. Dunn, yaitu efektivitas, efisiensi, kecukupan, dan responsifitas. Metode penelitian ini menggunakan metode kualitatif dengan teknik deskriptif, dalam pemilihan informan menggunakan metode purposive sampling. Adapun teknik yang peneliti gunakan adalah wawancara, obsevasi, dan dokumentasi. Analisis data yang digunakan adalah analisis data lapangan. Komponen dalam analisis data diantaranya, reduksi data, display data, mengelompokkan data, dan menyimpulkan. Berdasarkan hasil penelitian data dapat disimpulkan bahwa program KTP-el sudah dicapai namun belum maksimal, dimana masih banyaknya ketidaksesuaian NIK di Kartu Keluarga dengan KTP-el, kemudian seiring dengan kekosongan balngko KTP-el menyebabkan pelayanan menjadi terlambat dan banyaknya data duplicated record karena belum adanya pengecekkan biometrik. Adapun saran dalam penelitian ini adalah perlunya dilakukan sosialisasi secara komprehensif dan perlunya ditambahkan aplikasi untuk cek biometrik supaya lebih efektif dan efisien.
\end{abstract}

\section{Kata kunci: Evaluasi, Kebijakan, dan KTP-el.}

Abstract; The purpose of this study was to determine the Evaluation of the Implementation of Recording of KTP-el in the Department of Population and Civil Registration of Buton Regency. This study uses William N. Dunn's evaluation criteria theory, namely effectiveness, efficiency, adequacy, and responsiveness. This research method uses qualitative methods with descriptive techniques, in the selection of informants using purposive sampling method. The techniques that researchers use are interviews, observation, and documentation. Analysis of the data used is field data analysis. Components in data analysis include, data reduction, data display, grouping data, and concluding. Based on the results of the research, it can be concluded that the KTP-el program has been achieved but not yet maximized, where there are still many incompatible NIKs on the Family Card with the KTPel, then along with the vacancy of the KTP-el board, the service has been delayed and the number of duplicated records due to the absence biometric checking. The suggestion in this research is the need for comprehensive socialization and the need to add applications to check biometrics to make it more effective and efficient.

Keywords: Evaluation, Policy, KTP-el. 


\section{Pendahuluan}

Administrasi kependudukan menurut Undang-Undang No.23 Tahun 2006 tentang Administrasi Kependudukan Pasal 1 ayat (1) adalah rangkaian kegiatan penataan dan penertiban dokumen serta data kependudukan melalui pendaftaran penduduk, pencatatan sipil, pengelolaan informasi administrasi kependudukan serta pendayagunaan hasilnya untuk pelayanan publik dan sektor lain. Administrasi Kependudukan sebagai suatu sistem diharapkan dapat memberikan pemenuhan hak-hak administratif, seperti pelayanan publik serta perlindungan yang berkenaan dengan dokumen kependudukan, tanpa adanya perlakuan yang diskriminatif.

Penyelenggaraan kependudukan bertujuan untuk mewujudkan tertib administrasi kependudukan secara nasional dan terpadu. Tertibnya database kependudukan akan membangun database kependudukan yang akurat ditingkat kabupaten/kota, provinsi dan pusat yang mana tersambung (online) dengan provinsi dan pusat menggunakan SIAK (Sistem Infomasi Administrasi Kependudukan). Dalam UU RI No. 24 Tahun 2013 disebutkan bahwa Sistem Informasi Administrasi Kependudukan atau yang disingkat SIAK adalah sistem informasi yang memanfaatkan teknologi informasi dan komunikasi untuk memfasilitasi pengelolaan informasi administrasi kependudukan di tingkat penyelenggara dan instansi pelaksana sebagai satu kesatuan.

Tertib dalam penerbitan NIK (Nomor Induk Kependudukan) yaitu setiap penduduk wajib memiliki NIK. Nomor Induk Kependudukan wajib dicantumkan pada setiap dokumen kependudukan dan dijadikan dasar penerbitan paspor, SIM, NPWP dan penerbitan dokumen lainnya. Dalam rangka mewujudkan kepemilikan 1 (satu) KTP untuk 1(satu) penduduk, maka dari itu diperlukan sistem keamanan/pengendalian dari sisi administrasi ataupun teknologi informasi dengan melakukan verifikasi dan validasi dalam sistem database kependudukan. Kemudian tertibnya dokumen kependudukan dimaksudkan agar tidak adanya dokumen kependudukan yang ganda dan pemalsuan data. Salah satu bentuk dokumen kependudukan yang penting di Indonesia adalah Kartu Tanda Penduduk (KTP).

Pemerintah melalui Kementerian Dalam Negeri selaku pihak yang berkewajiban dan bertanggung jawab dalam menyelenggarakan administrasi kependudukan pada tahun 2006 membuat suatu program strategis nasional yaitu KTP berbasis Nomor Induk Kependudukan atau yang sekarang disebut KTP elektronik 
(KTP-el) sebagai salah satu langkah pencapaian e-government untuk mengatasi problematika kependudukan terutama pencatatan dan kependudukan, KTP ganda, pemalsuan KTP yang diharapkan akan mendukung terciptanya keakuratan data penduduk. KTP-el bertujuan untuk memberlakukan data kependudukan secara nasional. Sehingga seorang warga negara hanya memiliki satu KTP yang berlaku di wilayah administratif manapun di Indonesia.

KTP-el merupakan dokumen kependudukan yang memuat sistem keamanan/ pengendalian baik dari administrasi maupun teknologi informasi dengan berbasis pada database administrasi kependudukan. KTP-el sebagai kartu identitas penduduk berbasis Nomor Induk Kependudukan (NIK) yang dilengkapi dengan rekaman elektronik yang berisi biodata, foto, sidik jari, iris mata dan tanda tangan penduduk. KTP-el merupakan sebuah inovasi yang dilakukan pemerintah yang bertujuan untuk mewujudkan kepemilikan satu KTP satu penduduk.

Pembuatan KTP elektronik juga memanfaatkan teknologi informasi yaitu menggunakan sistem pengamanan biometrik, seperti fingerpint (sidik jari) dan pemindai mata. Selain itu, untuk mendukung pembuatan KTP elektronik ini diperlukan alat-alat seperti komputer, signature pad, kamera, dan lain-lain. Data penduduk yang telah terekam secara digital kemudian akan dikirimkan melalui jaringan internet kepada pemerintah pusat dan disimpan dalam satu database nasional. Di masa mendatang database tersebut dapat diakses oleh masyarakat untuk mengurus surat perizinan, pembukaan rekening bank, dan fasilitas pelayanan publik lainnya. (Sumber : Draft Materi sosialisasi pelaksanaan KTP-el oleh DKCS Kabupaten Buton Tahun 2017)

KTP-el menjadi sangat penting dikarenakan dalam beberapa tahun terakhir ini, masyarakat Indonesia dihadapkan pada beberapa permasalahan yang berkaitan dengan lemahnya sistem Administrasi Kependudukan di Indonesia. Diantara masalah tersebut adalah mulai dari orang yang meninggal yang masih mendapatkan hak suara ataupun kepemilikan KTP ganda yang menyebabkan permasalahan pada kepemilikan hak suara ganda dalam pemilu. Jumlah KTP palsu yang sangat besar dapat dipastikan bahwa dengan menggunakan KTP manual pemerintah sering mengalami kecolongan dalam mengawasi penggunaan KTP manual, karena KTP manual dapat dibuat dengan mudah dimana saja, apalagi jika memiliki orang dalam disebuah instansi kecamatan.

Sejauh ini program KTP-el sudah dilaksanakan hampir di seluruh Indonesia. 
Di Kabupaten Buton berdasarkan data Primer Disdukcapil Kabupaten Buton 2017 bahwa ada peningkatan dari kepemilikan Kartu Tanda Penduduk Elektronik dua tahun terakhir, Tahun 2016 jumlah kepemilikan KTP-el adalah 45.388 jiwa dari 98.156 jiwa penduduk atau 52.768 jiwa penduduk yang belum memiliki KTPel dengan persentase sebesar 53,76\%. Sedangkan ditahun 2017 dari total jumlah penduduk yang wajib memiliki KTP-el yakni 99.352 jiwa yang memiliki KTP-el sejumlah 48.627 jiwa atau 50.725jiwa belum memiliki KTP-el dengan pesentase $51,06 \%$. Sementara progres capaian kepemilikan KTP-el hingga Desember 2017telah tercapai. Namun kenyataannya masih banyak permasalahan antara lain: KTP-el ganda, alamat tidak benar dan tanggal lahir yang juga tidak sesuai, ditambah lagi lambatnya proses distribusi blangko KTP-el yang diperoleh Kabupaten Buton menjadi hambatan dalam proses pembuatan atau revisi KTP-el yang bermasalah.

Berdasarkan uraian latar belakang permasalahan diatas, maka fokus penelitian ini adalah untuk melihat bagaimana evaluasi pelaksanaan perekaman kartu tanda penduduk elektronik pada Dinas Kependudukan dan Catatan Sipil Kabupaten Buton.

Adapun tujuan penelitian ini adalah untuk mengetahui Evaluasi Pelaksanaan
Perekaman Kartu Tanda Penduduk Elektronik pada Dinas Kependudukan dan Catatan Sipil Kabupaten Buton

\section{Metode Penelitian}

Penelitian ini menggunakan metode penelitian deskriptif kualitatif yaitu suatu metode untuk menggambarkan atau melukiskan suatu peristiwa untuk diambil kesimpulan secara umum, Hadi (1984: 3). Oleh sebab itu penelitian ini berusaha mendapatkan informasi selengkap mungkin mengenai evaluasi pelaksanaan perekaman KTP-el di Dinas Kependudukan dan Pencatatan Sipil Kabupaten Buton. Penelitian ini terdiri dari satu variabel yakni evaluasi pelaksanaan perekaman kartu tanda penduduk elektronik. Penentuan sampel dengan teknik purposive sampling berjumlah 9 orang, baik dari pegawai Dinas Dukcapil Kabupaten Buton maupun dari masyarakat pemilik KTP-el.

Sumber data penelitian ini terdiri atas : 1) data primer yakni data yang langsung diperoleh dari lapangan melalui observasi dan wawancara; 2) data sekunder yakni data yang diperoleh melalui penelusuran berbagai dokumentasi yang relevan dengan masalah penelitian. Teknik analisis data menggunakan model interkatif yang telah dikembangkan oleh Miles dan Huberman (2007: 15-21) yaitu pengumpulan data, reduksi data, penyajian data dan penarikan kesimpulan. 


\section{Pembahasan}

Uraian pembahasan dalam penelitian ini dengan mengacu pada enam indikator meliputi: efektivitas, efisiensi, kecukupan, perataan, responsivitas dan ketepatan.

\section{a. Efektivitas}

Berdasarkan hasil penelitian, pencapaian target pelaksanaan perekaman KTP-el sudah mendekati target yang diharapkan. Namun perubahan yang hendak dicapai belum bisa dirasakan, yaitu belum tertibnya administrasi kependudukan dengan masih banyak ditemukan data ganda, adanya ketidak sesuaian Nomor Induk Kependudukan KTP-el dengan NIK dalam Kartu Keluarga, sebagaimana pelaksanaan KTP-el ini untuk mewujudkan satu NIK untuk satu penduduk. Saat ini Disdukcapil Kabupaten Buton masih membutuhkan waktu supaya pelaksanaan KTP-el di Kabupaten Buton bisa benar-benar efektif, kendati masih ada sejumlah data kependudukan yang perlu diverifikasi dan divalidasi.

Di sadari bahwa program KTP-el ini masih terdapat beberapa hambatan dalam pelaksanaannya yaitu masih kurang memadainya sarana dan prasarana di Dinas Kependudukan dan Pencatatan Sipil. Alat perekaman sering mengalami eror atau tidak berfungsi seperti saat awal dilaksanakannya program ini, kebanyakan alat pemindai mata juga sering mengalami gangguan. Pada awalnya disetiap kecamatan memiliki satu set alat perekaman namun dalam beberapa waktu terakhir ini juga sering mengalami gangguan teknis. Kemudian hambatan lainnya yakni keterbatasan blangko KTP-el yang sering kehabisan dalam beberapa waktu lamanya, kadang bermingguminggu bahkan sampai berbulan-bulan menunggu. Sementara pengadaan dan penyediaan blangko KTP-el sesuai Peraturan Presiden No.26 Tahun 2009 merupakan kewenangan pusat yang dilakukan secara bertahap. Dalam pengadaan blangko KTP-el, masalahnya adalah Kemendagri tidak mengacu pada berapa banyak KTP-el yang dibutuhkan oleh masyarakat di daerah. Blangko KTP-el yang didistribusikan sejauh ini hanya berpatokan pada data perekaman yang masuk ke pusat, sementara kebutuhan riil blangko KTP-el melampauhi jumlah anggota masyarakat yang memerlukah KTP-el.

\section{b. Efisiensi}

Efisiensi merupakan salah satu bentuk kriteria didalam proses evaluasi pelaksanaan KTP-el di Dinas Kependudukan dan Catatn Sipil Kabupaten Buton. Berdasarkan hasil penelitian, Disdukcapil selaku pelaksanaa dalam upaya percepatan pencapaian perekaman KTP-el memberikan kemudahan kepada masyarakat dengan mengadakan 
pelayanan keliling atau jemput bola yang dilakukan tiap kecamatan.

Selanjutnya prosedur dalam pembuatan KTP-el diawali dengan surat pengantar dari Kelurahan/Desa tempat domisili penduduk. Tetapi saat ini sesuai dengan surat edaran dari Kemendagri Nomor 471.13/24150 tentang Pelayanan Jemput Bola Perekaman KTP-el, Menteri Dalam Negeri menegaskan, seiring dengan semakin tertatanya database kependudukan seluruh indonesia, maka dalam pelayanan perekaman, penerbitan, dan penggantian KTP-el yang rusak dan tidak berubah elemen data kependudukan, perlu penyederhanaan prosedur. Cukup dengan menunjukkan foto copy kartu keluarga dan tanpa pengantar dari Kelurahan/Desa dan Kecamatan.

Namun dalam praktiknya masih terjadi pro dan kontra karena masih belum sesuai dengan instruksi yang telah dikeluarkan oleh Kemendagri, hal ini terbukti untuk pembuatan KTP-el di kecamatan masih perlu pengantar dari Kelurahan/Desa. Kebijakan yang dibuat Kemendagri dalam penyederhanaan prosedur pembuatan KTP-el Kabupaten Buton belum terlaksana dengan baik.

Temuan di lapangan, mengenai kriteria efisiensi yang berkenaan dengan ketepatan waktu dalam pembuatan KTP-el, dapat diketahui bahwa KTP-el belum efisien. Karena kekosongan blangko
Disdukcapil maka pembuatan KTP-el tidak tepat waktu yaitu lebih dari 14 hari kerja, padahal sesuai SOP pelayanan pembuatan KTP-el paling lama adalah 14 hari kerja. Untuk mengatasi kekososngan blangko tersebut Dinas Kependudukan dan Pencatatan Sipil Kabupaten Buton mengeluarkan Surat Keterangan Pengganti KTP-el. Surat tersebut dibuat hanya mereka yang sudah memiliki NIK dalam KTP-el atau yang sudah berstatus "Print Ready Record" atau sudah siap cetak. Surat tersebut ditandatangani Kepala Dinas, dan didalam Surat Keterangan Pengganti KTPel tertulis bahwa surat keterangan tersebut sebagai pengganti KTP-el yang bersifat sementara yang dapat digunakan untuk kepentingan pengurusan BPJS, Perbankan dan lainnya.

Berdasarkan hasil penelitian lapangan menunjukkan bahwa penggunaan surat keterangan tersebut tidak benarbenar efektif dapat digunakan untuk pelayanan publik layaknya KTP-el asli. Di sejumlah instansi pemerintah dan swasta tetap menolak penggunaan Surat Keterangan Pengganti KTP-el dengan berbagai alasan prosedural yang berlaku di instansi masing-masing. Saat ini sudah sekitar 95\% penduduk Indonesia yang melakukan perekaman KTP-el, sehingga semakin banyak yang merekam semakin lama pula untuk proses penunggalan hasil perekaman KTP-el. Artinya, penduduk 
yang baru melakukan perekaman tentu membutuhkan waktu yang sedikit lebih lama menunggu pencetakan KTP-el nya.

\section{c. Kecukupan}

Indikator ini merupakan salah satu bentuk kriteria dalam proses evaluasi pelaksanaan KTP-el di Disdukcapil Kabupaten Buton. Dalam hal ini hasil yang diinginkan merupakan kesesuaian proses pelaksanaan KTP-el dengan kepuasan dan tinggkat kebutuhan masyarakat. Kebijakan yang dikeluarkan oleh pemerintah biasanya mengharapkan suatu perubahan yng lebih baik dan dapat memuaskan dalam pelaksanaannya.

Kriteria kecukupan yaitu berkaitan dengan kemampuan program KTP-el dalam menekan jumlah data ganda dan berkaitan dengan kecukupan sarana dan prasarana dalam pelaksanaan program KTP-el. Pada temuan di lapangan, program KTP-el sedikit demi sedikit mengurangi jumlah ganda. Hanya saja masih butuh waktu, karena masih banyak data yang perlu dirapikan sehingga dapat mewujudkan tertib NIK, tertib Database serta tertib dokumen.

Kecukupan juga berkenaan dengan sejauh mana kebijakan tersebut dalam pencapaian target, dapat menurunkan jumlah data penduduk ganda di Kabupaten Buton. Untuk mencapai target tentunya dibutuhkan sarana dan prasarana yang memadai guna optimalisasi dalam pelaksanaan program KTP-el di Kabupaten Buton ini. Permasalahan blangko kosong, peralatan perekaman yang sudah mulai kurang berfungsi, serta kualitas SDM yang perlu ditingkatkan menyebabkan hasil yang diinginkan dalam program KTP-el ini masih belum begitu optimal.

\section{d. Perataan}

Perataan berkaitan dengan bagaimana suatu kebijakan yang dibuat dan dilaksanakan dapat terdistribusi pelayanannya atas dasar kesamaan manfaat yang diberikan. Pada proses pelaksanaan KTP-el oleh Disdukcapil Kabupaten Buton, pihak pemerintah harusnya melaksanakan dengan adil tanpa adanya diskriminasi sehingga proses pelaksanaan KTP-el dalam upaya penertiban administrasi kependudukan dapat dirasakan oleh seluruh lapisan masyarakat.

Berdasarkan hasil penelitian, pelaksanaan sosialisasi yang telah dilakukan oleh Dinas Kependudukan dan Pencatatan Sipil sebagai pelaksana teknis dalam program KTP-el yang telah menunjuk untuk setiap kecamatan, belum mencakup semua karena peserta sosialisasi terbatas 60 orang. Disdukcapil menginginkan agar peserta yang hadir adalah mereka yang belum pernah mengikuti sosialisasi sebelumnya, bukan perwakilan dari Kelurahan/Desa yang sudah pernah mendapat sosialisasi. Selain 
sosialisasi yang disampaikan oleh Disdukcapil kepada peserta belum diteruskan secara merata kepada masyarakat di desanya masing-masing. Akibatnya masih ada sebagian masyarakat yang belum benar-benar memahami program KTP-el tersebut. Berdasarkan keterangan informan bahwa pihak pelaksana sangat penting perannya guna keberhasilan pelaksanaan program KTP-el. Dalam sosialisasi tersebut dinas juga terkendala dengan anggaran yang terbatas. Sebab sebuah program kebijakan yang dibuat oleh pemerintah sudah semestinya didukung oleh sumber dana yang cukup, karena kebijakan tidak akan berjalan dengan baik jika tidak didukung oleh anggaran yang memadai.

\section{e. Responsivitas}

Responsivitas berkenaan dengan seberapa jauh suatu kebijakan dapat memuaskan kebutuhan, preferensi, atau nilai kelompok-kelompok masyarakat tertentu. Program pelaksanaan KTP-el ini diharapkan mampu mendorong seluruh jajaran pemerintahan mulai dari pusat hingga daearh untuk memenuhi berbagai tuntutan kebutuhan masyarakat agar hasil yang dicapai dapat lebih maksimal dan optimal serta memberikan kemudahan terhadap kebutuhan seluruh lapisan masyarakat yang dilayani.

Berdasarkan hasil penelitian, pelaksanaan KTP-el di Disdukcapil
Kabupaten Buton mendapatkan respon yang baik. Dengan adanya instruksi Kemendagri tentang estimasi waktu perekaman KTP-el paling lambat 30 september 2006, hal ini mendorong masyarakat datang ke kecamatan dan dinas untuk melakukan perekaman KTP-el. Sebelum adanya instruksi pemerintah, biasanya pelayanan pembuatan KTP-el baik di kecamatan-kecamatan maupun di kantor Disdukcapil sendiri tidak terlalu ramai.

Namun saat berlakunya instruksi tersebut, jumlah antrian untuk perekaman KTP-el dari hari ke hari terus menagalami peningkatan. Karena masih banyaknya jumlah anggota masyarakat yang belum melakukan perekaman KTP-el, sehingga hal ini pula yang mendorong pemerintah untuk memperpanjang waktu perekaman sampai dengan pertengahan tahun 2017.

Antusiasme masyarakat yang cukup tinggi rupanya tidak diimbangi dengan sarana dan prasarana yang memadai seperti keterbatasan jumlah blangko KTPel. Kondisi ini tentu menjadi paradoks, karena disatu sisi pemerintah mengistruksikan agar msyarakat melakukan perekaman KTP-el tetapi disaat yang bersamaan pemerintah juga belum sepenuhnya memenuhi ketersediaan blangko KTP-el, sehingga tidak sedikit anggota masyarakat yang merasa kecewa. 


\section{f. Ketepatan}

Kriteria ini berkenaan dengan apakah suatu kebijakan dapat memberikan manfaat bagi masyarakat. Pada temuan dilapangan program KTP-el memberikan dampak yang baik bukan saja untuk masyarakat sendiri, melainkan juga untuk memberikan data valid yang dapat digunakan untuk berbagai keperluan seperti kebutuhan data pemilu atau data kependudukan yang berhubngan dengan rencana pembangunan dimasa datang.

Berdasarkan temuan dilapangan, masyarakat mengungkapkan bahwa program KTP-el ini diharapkan dapat meminimalisir berbagai tindak kejahatan seperti penipuan, pemalsuan dokumen dan terorisme. Karena satu NIK KTP-el untuk satu penduduk sehingga tidak bisa digandakan dan database menjadi lebih akurat.

\section{Kesimpulan}

Simpulan dalam penelitian ini adalah: 1) Program perekaman KTP-el yang diterapkan di Dinas Kependudukan dan Pencatatan Sipil Kabupaten Buton belum efektif, dikarenakan masih banyak mengalami kendala sehingga belum tercapainya tertib administrasi kependudukan; 2) Program ini belum efisien karena membutuhkan waktu yang lama bagi yang baru melakukan perekaman KTP-el. Semakin banyak yang melakukan perekaman KTP-el semakin lama penunggalan hasil perekaman KTP-el. 3) Masih belum terpenuhinya kebutuhan masyarakat secara merata karena Disdukcapil Kabupaten Buton sering kehabisan blangko KTP-el, diman pusat hanya memberikan blangko sesuai data perekaman yang masuk ke pusat padahal Kabupaten Buton memerlukan banyak blangko KTP-el; 4) Program KTP-el yang telah diterapkan di Disdukcapil Kabupaten Buton sudah tepat, karena seiring berjalannya waktu jumlah data ganda akan semakin sedikit sehingga database menjadi benar-benar valid. 


\section{Daftar Pustaka}

Agustino, Achmadi dan Narbuko 2004. Metode Penelitian.Bumi Aksara. Jakarta.

Arikunto, Suharsimi. 1998. Prosedur Penelitian Suatu Pendekatan Praktik, PT. Rineka Cipta. Jakarta.

Danim, Sudarwan. 2002. Menjadi Peneliti Kualitatif. Pustaka Setia. Bandung.

Islamy, Irfan. 2009. Prinsip-prinsip Perumusan Kebijaksanaan Negara. Bumi Aksara: Jakarta.

Leo. 2008. Politik dan Kebijakan Publik. AIPI: Bandung

Miles, Mathew dan Michael Huberman. 2007. Analisis Data Kualitatif (BukuSumber Tentang MetodeMetode

Baru).UniversitasIndonesia (UIPress).Jakarta

Moleong, Lexy. 2007. Metodologi Penelitian Kualitatif. PT Remaja Rosdakarya: Bandung

Nawawi, Ismail. 2013. Budaya organisasi kepemimpinan dan Kinerja.PT. Fajar Iterpratama Mandiri.Jakarta.Silalahi, Ulber. 2010. Metode Penelitian Sosial. Bandung: Refika Aditama.

Nugroho, R. 2012. Kebijakan Publik Formulasi, Implementasi dan Evaluasi.Jakarta : Gramedia.

Parsons, Wayne. 2008. Public Policy: Pengantar Teori dan Praktik
Analisis Kebijakan. Prenada Media: Jakarta.

Suandi, I Wayan.2010. Eksistensi Kebijakan Publik dan Hukum DalamPenyelenggaraan

Pemerintah Daerah.Bali Universitas Udayana.

Sudjarwo. 2004. Buku Pintar Kependudukan. Penerbit: PT. Grasindo. Jakarta.

Soekarno SD. 2003. Public Policy.Surabaya : Airlangga University Press.

Sugiyono. 2011. Metode Penelitian Kuantitatif dan Kualitatif dan R dan D.Bandung ParsonAlfabeta.

Winarno, Budi. 2012. Kebijakan Publik(Teori, Proses, dan Studi Kasus). Buku Seru: Yogyakarta.

\section{Peraturan Perundang-Undangan:}

Undang-Undang No.23 Tahun 2006 tentang Administrasi Kependudukan.

Undang-UndangRepoblik Indonesia Nomor 24 Tahun 2013 tentangPerubahan Atas Undang-Undang Nomor 23 Tahun 2006Tentang Administrasi Kependudukan.

Peraturan Presiden RI No.26 Tahun 2009 tentang Pelaksanaan Kartu Tanda Penduduk berbasis Nomor Induk Kependudukan.

Instruksi Presiden nomor 3 tahun 2003 tentang Kebijakan dan Strategi Nasional Pengembangan egovernment. 